\title{
Joint Inventory, Pricing, and Advertising Decisions with Surplus and Stockout Loss Aversions
}

\author{
Bing-Bing Cao, ${ }^{1}$ Zhi-Ping Fan, ${ }^{1,2}$ Hongyan Li, ${ }^{3}$ and Tian-Hui You ${ }^{1}$ \\ ${ }^{1}$ Department of Information Management and Decision Sciences, School of Business Administration, Northeastern University, \\ Shenyang 110167, China \\ ${ }^{2}$ State Key Laboratory of Synthetical Automation for Process Industries, Northeastern University, Shenyang 110819, China \\ ${ }^{3}$ Department of Economics and Business Economics, School of Business and Social Sciences, Aarhus University, 8210 Aarhus, Denmark
}

Correspondence should be addressed to Zhi-Ping Fan; zpfan@mail.neu.edu.cn

Received 29 December 2015; Accepted 26 April 2016

Academic Editor: Francisco R. Villatoro

Copyright (C) 2016 Bing-Bing Cao et al. This is an open access article distributed under the Creative Commons Attribution License, which permits unrestricted use, distribution, and reproduction in any medium, provided the original work is properly cited.

The newsvendor models considering decision-makers' behavioral factors remain a fruitful research area in operation management field in past decade. In this paper, we further extend the current literatures to look into joint inventory, pricing, and advertising decisions considering loss aversion effects under the newsvendor setting. The purpose is to explore how the loss aversions affect the optimal policy of order quantity, price, and advertising effort level. We present an integrated utility model to measure both economic payoff and loss aversion utility of the newsvendor, where surplus loss aversion and stockout loss aversion are first separately defined and quantified. Then, we analyze the optimal solution conditions of the integrated model under exogenous and endogenous price cases, respectively. Under exogenous price case, we find that the uniquely optimal policy exists and is presented in the closed form. Under endogenous price case, the optimal policy is determined under mild conditions; we also provide the solutions when order quantity factor or advertising effort level is fixed in this case. In addition, the sensitivity analysis shows that the loss aversions affect the optimal decisions of order quantity, price, and advertising effort level in a systematic way.

\section{Introduction}

Both business practices and academic research show that the decisions on operations management $(\mathrm{OM})$ in real world often deviate from the optimal solutions of the traditional analytical models in operations research (see [1-3]). This is because the traditional analytical models are usually based on a strong assumption of the newsvendor's perfect rationality. In reality, the newsvendor usually cannot exhibit perfect rationality but can exhibit some psychological behaviors which cause the derivation of the decisions from the traditional optimal solutions. Hence, it is difficult to describe the newsvendor's real decision-making process using the traditional analytical models. In order to bridge the gap between traditional models and real world situations, some scholars conduct studies on the integration of behavioral factors into the traditional analytical models (see [4-6]).

The behavioral factors which have been identified in the $\mathrm{OM}$ area include bounded rationality (see $[6,7]$ ), reference dependence (see [8]), decision bias (see [9]), fairness concern (see $[10,11])$, overconfidence (see [12]), mental accounting (see [13]), and loss aversion (see [5, 14, 15]). We will concentrate on the behavioral factor of loss aversion. The loss aversion implies that the newsvendor is more sensitive to the gains than to the absolutely commensurable losses. It is reasonable in the real business environment because the decision-makers may perform different preferences from risk-neutrality. It can be seen from the existing literatures that the loss aversion effect has been identified and addressed in the $\mathrm{OM}$ area (see [16-18]). Although the existing studies have made great contributions to the $\mathrm{OM}$ problem considering behavioral factors, the study on the joint inventory, pricing, and advertising decisions considering the loss aversion is still lacking. In this paper, we look into joint inventory, pricing, and advertising decisions considering the loss aversion under the newsvendor setting. Given that the retailer may have different sensitivity to the loss caused by the overstock and 
the loss caused by the out-of-stock, the loss aversion is distinguished as the surplus loss aversion and the stockout loss aversion. We focus on discovering the impact of the two loss aversions on the joint inventory, pricing, and advertising effort level decisions. Since price and advertising are the most important and direct marketing tools to balance demand and supply when facing a stochastic demand, we consider a price and advertising effort level dependent demand function with a stochastic demand factor. The loss-averse newsvendor needs to determine the optimal order quantity, retail price, and the advertising effort level before the beginning of the selling season.

Given the great complexity of the joint decision-making problem, we first analyze the economic payoff and loss aversion utility of the newsvendor separately and then establish an integrated utility function based on Bell's integrated model (see [19]). In integrated function, the economic payoff is measured by the profit function; the loss aversion utility consists of two parts: a surplus loss aversion utility and a stockout loss aversion utility. The loss aversion utilities are measured by a linear function. Furthermore, the optimal solution conditions on the inventory, price, and advertising effort level are presented by analyzing the characteristics of the integrated utility function under the exogenous price case and the endogenous price case.

The main contribution of the study is extending the existing loss-averse newsvendor models and joint inventory and pricing models to be more realistic settings. In detail, we first identify and quantify two types of loss aversions, that is, stockout loss aversion and surplus loss aversion, in the newsvendor environment. Next, based on the utility maximization theory, we integrate the economic payoff and the loss aversion utility and determine a total utility model. Furthermore, we provide the structural properties of the optimal solutions to the integrated model under the exogenous price case and the endogenous price case. Under the exogenous price case, the optimal order quantity and advertising effort level exist and are given in the closed form. Under the endogenous case, the optimal order quantity, price, and advertising effort level can be determined simultaneously under mild conditions. In addition, we also provide the optimal solutions to the joint decision model when the order quantity factor or the advertising effort level is fixed. Moreover, the sensitivity analysis shows the robustness of research results. Finally, we give a numerical example and show that both the stockout loss aversion and the surplus loss aversion affect the optimal order quantity, price, and advertising effort level in a systematic way.

The rest of the paper is organized as follows. Section 2 outlines related literatures. Section 3 describes the newsvendor's utility framework and constructs the utility model. Section 4 solves the loss-averse newsvendor problem with advertising effect under the exogenous price case. Section 5 solves the problem under the endogenous price case and provides the optimal solutions when the order quantity factor or the advertising effort level is fixed. Section 6 concludes with a brief discussion of future research directions. All proofs are provided in the technical appendix.

\section{Literature Review}

Our study is closely related to three streams of literatures: the loss-averse newsvendor models, the newsvendor and pricing models, and the advertising optimization models. There is a great amount of studies in these areas, and it is difficult to exhaust the literatures. For the sake of brevity, we only focus on the latest and most representative studies here.

Extensive behavioral experiments show that the psychological behaviors play an important role in newsvendor's decisions under uncertainty (see $[6,8,19-24])$. The loss-averse newsvendor problem has been a fruitful research topic in past few years. Lee et al. [5] analyze the impact of the loss aversion of the newsvendor on his/her optimal options decisions. They find that a loss-averse newsvendor will order less without supplying options. Herweg [14] extends the classical newsvendor problem with the expectation-based loss aversion. They state the order quantity for the loss-averse newsvendor is less than that for the risk-neutral newsvendor. Wang and Webster [17] focus on the loss aversion in classic newsvendor settings and find that loss aversion affects the optimal inventory policy. They also find that optimal order quantity may increase in wholesale price but decrease in retail price in this situation. Wang [18] extends the standard newsvendor problem into the game setting where the multiple loss-averse newsvendors and one risk-neutral supplier are considered and shows that the newsvendors' total order quantity increases with the increase of loss aversion. Nagarajan and Shechter [23] address the newsvendor problem based on the prospect theory through an experimental study. They maintain that the real order quantity deviates from the theoretical optimal order quantity, and the prospect theory cannot explain the reason of the deviation. Ma et al. [25] study the loss-averse newsvendor problem with two ordering opportunities and market information updating and build a penalty model for the loss-averse newsvendor to obtain the target profit. Xu et al. [26] focus on the optimal decision for the loss-averse newsvendor problem under conditional value at risk. They introduce the legacy loss into the analysis of the loss-averse newsvendor problem and analyze the effect of the legacy loss on the optimal order quantity.

In addition, the newsvendor problem is also analyzed with other psychological behaviors such as reference dependence, decision bias, bounded rationality, and inequality aversion. Interested readers may please refer to the recently published papers for a thorough review [2, 3, 6, 22, 27, 28]. Although the above studies have made great contributions to the newsvendor model with loss aversion, they seldom consider the price and the advertising effect simultaneously, and they do not describe clearly the impacts of the aversions to the surplus loss and stockout loss on the optimal policy.

The newsvendor and pricing problem is the most typical topic in the interface between the $\mathrm{OM}$ and marketing. It is one of the extensions of the classical newsvendor model by considering the endogenous price and refers to the determination of the order quantity and price in order to maximize the newsvendor's expected profit in an uncertain demand framework (see $[29,30])$. The newsvendor and pricing model is a fundamental and significant model in OM (see [5]) and 
has attracted continuously extensive attention from both the academia and the practice. We refer the interested readers to $[29,31-33]$ for detailed literature review.

Advertising effort is another decision variable in our study and works as one of the indispensable marketing tools to increase demands. Recently, there are increasing interests from operation researchers about the joint OM and advertising decisions. For detailed survey of the advertising effect and its extensions, we refer the interested readers to [34-40]. However, how to integrate the newsvendor problem, pricing, and advertising effort level with the loss aversion behavior remains unresolved. But it can be seen that several studies attempt the integration of OM decisions, advertising effort, and behavioral factors. For example, Zhang et al. [41] study the cooperative advertising with reference price effect in a vertical supply chain and find that the firm will invest more in national advertising if impact of the reference price on the optimal policy is larger. Yang et al. [42] introduce the inequality aversion into the research on the cooperative advertising in a distribution channel. By equivalent analysis, they state that the channel coordination can be achieved under the mild conditions.

Our study is a realistic extension of the aforementioned papers, but it differs from them significantly in that the psychological behaviors, that is, loss aversions, of the newsvendor and advertising effect are simultaneously taken into account and that solutions for both the exogenous price case and the endogenous price case are presented.

\section{The Formulations}

We consider joint inventory, pricing, and advertising decisions for a loss-averse newsvendor with newsvendor settings. In this problem, apart from the traditional business objective of economic payoff, the newsvendor is driven by the economic payoff and loss aversion. Here, we apply the classic weighted sum utility model proposed by Bell [19] to integrate the economic payoff and loss aversion utility; it is shown below:

$$
\begin{aligned}
\text { Utility }= & \text { economic payoff } \\
& + \text { psychological satisfaction, }
\end{aligned}
$$

where the economic payoff can be measured by a newsvendor's profit during the selling season; the psychological satisfaction means also loss aversion utility and can be measured by the psychological differences between the realized profit and the expected profit of the newsvendor. We further present the profit and loss aversion utility of the newsvendor in detail in the following sections.

3.1. Profit: Economic Payoff of the Newsvendor. In the joint inventory, pricing, and advertising decisions, the newsvendor places an order of quantity $Q$ at a unit purchasing cost $c$ and sells at price $p$. The inventory cannot be replenished during the selling season. In addition, the newsvendor also does advertising to promote the products, and the advertising effort level $A$ depends on the newsvendor's advertising investment. The price, the advertising effort level, and the market uncertainty can affect the demand. Without loss of generality, consider that the demand is composed of the two parts (see $[43,44])$. One is the deterministic part which is related to the price and advertising effort level. Usually, this part is nonincreasing in the price (see $[29,45,46])$ and nondecreasing in the advertising effort level (see [47-49]). The other is the stochastic part which is denoted by a random factor $\varepsilon, \varepsilon \in[M, N]$. Let $f(\varepsilon)$ and $F(\varepsilon)$ denote the probability density function and the cumulative distribution function of the random factor $\varepsilon$, respectively, and $\mu$ and $\sigma$ denote the mean and the standard deviation, respectively. The demand function can be additive or multiplicative (see [29, 45]). Since the optimal policies for the additive demand function can be easily adapted to the ones for the multiplicative demand function (see [46]) and the model is tractable for the additive demand function, we use the linear additive demand function; it is given by

$$
D(\varepsilon)=y(p)+k A+\varepsilon,
$$

where $y(p)=a-b p, a$ and $b$ denote the market size and the price sensitivity, respectively, $a>0, b \geq 0, A$ denotes the advertising effort level, $A \geq 0$, and $k$ denotes the advertising sensitivity, $k>0$. We assume that the advertising cost is convex in the advertising effort level and the cost function of the advertising effort level $A$ is $A^{2} / 2$. It is commonly used in literatures (see $[42,50-52]$ ). The parameters should be properly chosen to assure a positive demand for some range of $p$ and $A$. In addition, if there is unsatisfied customer demand at the end of the selling season, a shortage cost $s$ incurs, and if there is excess stock by end of the selling season, an salvage value $v$ incurs, where $p>c>v$.

Therefore, the profit function of the newsvendor can be written as

$$
\Pi= \begin{cases}(p-c) D-(c-v)(Q-D)-\frac{A^{2}}{2}, & D<Q \\ (p-c) Q-s(D-Q)-\frac{A^{2}}{2}, & D \geq Q\end{cases}
$$

3.2. Utility of Loss Aversion: Psychological Satisfaction. Loss aversion is first recognized by Kahneman and Tversky [53] in the framework of prospect theory, and it is an important psychological concept which receives increasing attention in the OM, especially in behavioral OM in recent years (see [5, 9, 16-18, 53-56]). Loss aversion implies that the newsvendor has different sensitivity to the perceived losses and the perceived gains (see $[16,17,57]$ ). Specifically, if the realized profit of the newsvendor is less than his expectation, then the newsvendor may feel extra loss beyond the actual economic lost sales. In fact, the newsvendor is often averse to the loss at the decision making phase.

Moreover, loss aversion is directly related to a reference point, denoted by $\Pi_{0}$. Generally, reference point can be the expected profit of the newsvendor (see $[5,16,17,55])$. In fact, the selection of reference point is also a subjective choice of the newsvendor and it is often relevant to the market environment, newsvendor's business strategies, and the competitive position. Theoretically, the reference point may be any arbitrary value in the profit range $\left[\Pi^{\mathrm{min}}, \Pi^{\mathrm{max}}\right]$ of the newsvendor, 


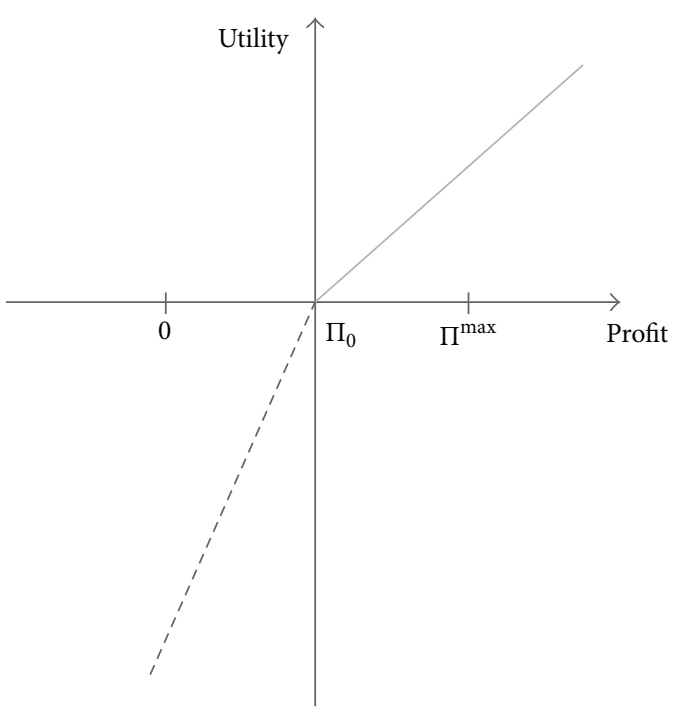

FIgURE 1: Loss aversion function.

where $\Pi^{\text {min }}$ denotes the theoretical minimum of the profit of the newsvendor, it may be negative, and $\Pi^{\max }$ denotes the theoretical maximum of the profit of the newsvendor, $\Pi^{\max }=$ $(p-c) D-A^{2} / 2$. Although, theoretically, the expected profit may be negative, the newsvendor usually does not choose a negative reference point since the businesses are always profit driven. Hence, the reference point is usually determined in the range of $\left[0, \Pi^{\max }\right]$.

Based on the above analysis, the newsvendor's perception on the gain and the loss can be described in Figure 1 (see $[9,16$, 17]). It is easy to see that the newsvendor perceives loss when the profit is less than the reference point $\Pi_{0}$, and the utility caused by the loss decreases faster than the utility caused by the gain increases when the profit is greater than the reference point.

In this paper, to analyze the impacts of the surplus loss aversion and the stockout loss aversion without distractions from the perceived gain, the theoretic maximum of the newsvendor's profit is considered as reference point; that is, $\Pi_{0}=\Pi^{\mathrm{max}}$. The theoretical maximum profit can be achieved when the order quantity is equal to the realized demand. In this case, the newsvendor will not perceive gain, and Figure 1 can be transformed into Figure 2 .

Furthermore, both overstock and out-of-stock cause loss of profit. Since the newsvendor may react differently to overstock and out-of-stock situations, we distinguish the loss caused by overstock and by out-of-stock here. The loss caused by overstock is named as surplus loss, and it occurs when the order quantity of the newsvendor is greater than the realized demand. The loss caused by out-of-stock is named as stockout loss, and it occurs when the order quantity of the newsvendor is lower than the realized demand. The newsvendor is usually averse to both the surplus loss and the stockout loss, and the degree of the surplus loss aversion may be different from the one of the stockout loss aversion.

Given the separation of the surplus loss aversion and the stockout loss aversion, we apply linear loss aversion function

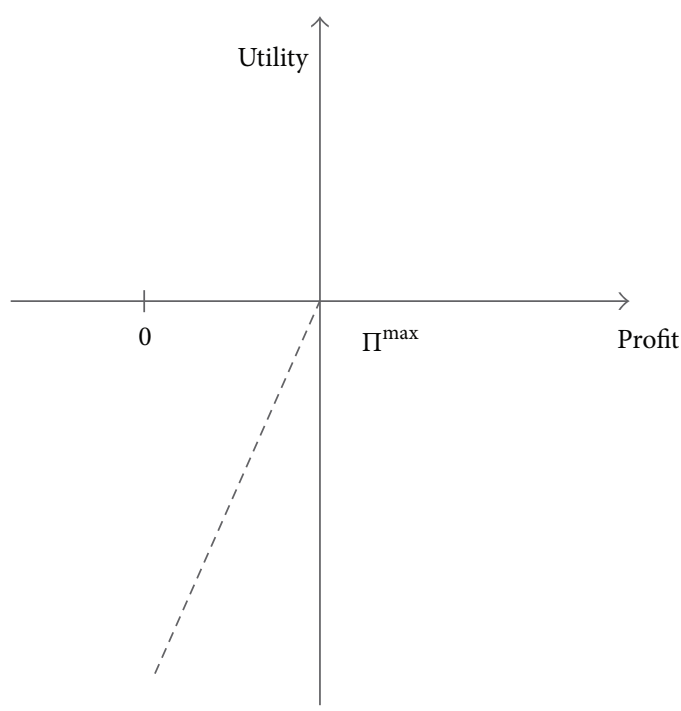

Figure 2: Loss aversion function when $\Pi_{0}=\Pi^{\text {max }}$.

to integrate the two types of loss aversion utilities (see $[9,16$, $58]$ ). In the following, we provide the specific illustration.

If the realized demand is lower than the order quantity, that is, $D<Q$, the newsvendor experiences the surplus loss $\Delta \Pi_{D<Q}$, and the surplus loss aversion utility is related to the difference between the reference point (i.e., theoretical maximum profit $\Pi_{0}$ ) and the real profit; it is denoted by

$$
\operatorname{LA}\left(\Delta \Pi_{D<Q}\right)=-\alpha \Delta \Pi_{D<Q},
$$

where $\alpha$ denotes the degree of the surplus loss aversion, $\alpha \geq 0$. The greater the parameter $\alpha$ is, the more averse the newsvendor is to surplus loss. If $\alpha=0$, the newsvendor is surplus loss neutral. Since $\Delta \Pi_{D<\mathrm{Q}}=\Pi^{\max }-\Pi_{D<\mathrm{Q}}=(c-$ $v)(Q-D)$, the surplus loss aversion utility can be written as

$$
\operatorname{LA}\left(\Delta \Pi_{D<Q}\right)=-\alpha(c-v)(Q-D) .
$$

Analogously, if the realized demand is greater than the order quantity, that is, $D>Q$, the newsvendor experiences the stockout loss $\Delta \Pi_{D \geq Q}$. The stockout loss aversion utility is denoted by

$$
\mathrm{LA}\left(\Delta \Pi_{D \geq Q}\right)=-\beta \Delta \Pi_{D \geq Q},
$$

where $\beta$ denotes the degree of the stockout loss aversion, $\beta \geq 0$. The greater the parameter $\beta$ is, the more sensitive the newsvendor is to stockout loss. If $\beta=0$, the newsvendor is the stockout loss neutral. Since $\Delta \Pi_{D \geq Q}=\Pi^{\max }-\Pi_{D \geq Q}=$ $(p-c+s)(D-Q)$, the stockout loss aversion utility can be written as

$$
\operatorname{LA}\left(\Delta \Pi_{D \geq Q}\right)=-\beta(p-c+s)(D-Q) .
$$

If $\alpha=\beta$, then the newsvendor exhibits the surplus loss aversion and stockout loss aversion with the same degree. If $\alpha>\beta(\alpha<\beta)$, then the newsvendor is more averse to the surplus (stockout) loss than to the stockout (surplus) loss. The 


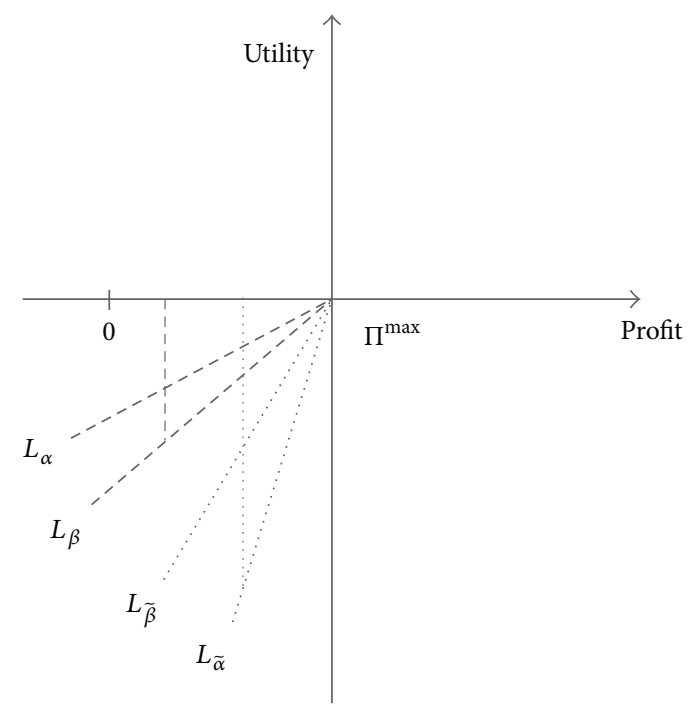

Figure 3: Surplus and stockout loss aversion function when $\Pi_{0}=$ $\Pi^{\max }$.

loss aversion utility curves may show two kinds of relations as described in Figure 3.

In Figure $3, L_{\alpha}$ represents the utility curve of the surplus loss aversion when $\alpha<\beta$ and $L_{\widetilde{\alpha}}$ represents the utility curve when $\alpha>\beta$. $L_{\beta}$ and $L_{\widetilde{\beta}}$ represent the utility curves of the stockout loss aversion when $\alpha<\beta$ and $\alpha>\beta$, respectively.
3.3. The Integrated Utility Model. While the economic payoff and the loss aversion utility are two separate decision objectives, they both are somehow related to and measured by the profit of the newsvendor. On the basis of (1), (3), (5), (7), and (8), a total utility of the newsvendor can be written as

$$
U=\Pi-\operatorname{LA}\left(\Delta \Pi_{D<Q}\right)-\operatorname{LA}\left(\Delta \Pi_{D \geq Q}\right) .
$$

Furthermore, if the realized demand is lower than the order quantity, that is, $D<Q$, we have the utility function; that is,

$$
\begin{aligned}
U_{D<Q}= & \Pi_{D<Q}-\operatorname{LA}\left(\Delta \Pi_{D<Q}\right) \\
= & (p-c) D-(c-v)(Q-D) \\
& -\alpha(c-v)(Q-D)-\frac{A^{2}}{2} .
\end{aligned}
$$

If the realized demand is greater than or equal to the order quantity, that is, $D \geq Q$, we have the utility function; that is,

$$
\begin{aligned}
U_{D \geq Q}= & \Pi_{D \geq Q}-\operatorname{LA}\left(\Delta \Pi_{D \geq Q}\right) \\
= & (p-c) Q-s(D-Q) \\
& -\beta(p-c+s)(D-Q)-\frac{A^{2}}{2} .
\end{aligned}
$$

Therefore, the total utility of the newsvendor can be written as

$$
U= \begin{cases}(p-c) D-(1+\alpha)(c-v)(Q-D)-\frac{A^{2}}{2}, & D<Q \\ (p-c) Q-s(D-Q)-\beta(p-c+s)(D-Q)-\frac{A^{2}}{2}, & D \geq Q\end{cases}
$$

For ease of exposition, we induce the order quantity factor $z=Q-y(p)-k A$ into the model. Thus, $D<$ $Q$ is equivalent to $\varepsilon<z$, and $D \geq Q$ is equivalent to $\varepsilon \geq z$. Then, by substituting the demand function (2) into (11), the integrated utility function can be rewritten as

$$
U= \begin{cases}(p-c)[y(p)+k A+\varepsilon]-(1+\alpha)(c-v)(z-\varepsilon)-\frac{A^{2}}{2}, & \varepsilon<z \\ (p-c)[y(p)+k A+z]-s(\varepsilon-z)-\beta(p-c+s)(\varepsilon-z)-\frac{A^{2}}{2}, & \varepsilon \geq z\end{cases}
$$

Then, our original decision making problem becomes the expected utility maximization problem with following objective function; that is,

$$
\begin{aligned}
\max \quad E[U] & \\
= & (p-c)[y(p)+k A+\mu] \\
& -(1+\alpha)(c-v) \Lambda(z)
\end{aligned}
$$

$$
-(1+\beta)(p-c+s) \theta(z)-\frac{A^{2}}{2},
$$

where $\Lambda(z)=\int_{M}^{z}(z-\varepsilon) f(\varepsilon) d \varepsilon$ and $\theta(z)=\int_{z}^{N}(\varepsilon-z) f(\varepsilon) d \varepsilon$.

For the convenience of the description, $E[U]$ can be rewritten as

$$
E[U]=\varphi(p)-(1+\alpha) L(z)-(1+\beta) S(z),
$$


where $L(z)=(c-v) \Lambda(z)$ denotes surplus loss when the order quantity is greater than the realized demand, $S(p, z)=(p-$ $c+s) \theta(z)$ denotes the stockout loss when the order quantity is lower than the realized demand, $\varphi(p)=(p-c)[y(p)+k A+$ $\mu]-A^{2} / 2$ denotes the expected profit function for the riskneutral newsvendor, and $\Omega(p, z)=\varphi(p)-L(z)-S(z)$ denotes the expected profit function for the loss-neutral newsvendor.

In the following, we will address the optimal solution conditions under the exogenous price case and the endogenous price case, respectively.

\section{Solutions under the Exogenous Price}

In some industries, the retail price of the product is determined by the competitive market, and the newsvendor does not have pricing power. This situation is named as exogenous price case. The exogenous price case is common in the furiously competitive market. In this section, we look into the order quantity and advertising effort level solutions when the retail price is exogenous.

According to (13), given price $p$, we have the first- and second-order partial derivatives of $E[U]$ with respect to the order quantity factor $z$ and the advertising effort level $A$; that is,

$$
\begin{aligned}
& \frac{\partial E[U]}{\partial z} \\
& =-(1+\alpha)(c-v) F(z) \\
& +(1+\beta)(p-c+s)[1-F(z)], \\
& \frac{\partial E[U]}{\partial A}=k(p-c)-A, \\
& \frac{\partial^{2} E[U]}{\partial z^{2}} \\
& =-[(1+\alpha)(c-v)+(1+\beta)(p-c+s)] f(z) \\
& <0 \text {, } \\
& \frac{\partial^{2} E[U]}{\partial z \partial A}=0, \\
& \frac{\partial^{2} E[U]}{\partial A^{2}}=-1<0, \\
& \frac{\partial^{2} E[U]}{\partial A \partial z}=0 .
\end{aligned}
$$

Then, the Hessian matrix is obtained; that is,

$$
\begin{aligned}
& H_{A z} \\
& =\left[\begin{array}{cc}
-1 & 0 \\
0 & -[(1+\alpha)(c-v)+(1+\beta)(p-c+s)] f(z)
\end{array}\right] .
\end{aligned}
$$

Since $H_{A z}$ is negative definite, the total utility function of the newsvendor (as shown in (13)) is jointly concave in order quantity factor $z$ and advertising effort level $A$. Therefore, according to (15) and (16), we have Lemmas 1 and 2 below.
Lemma 1. Given price $p$, there exists a unique optimal advertising effort level $A^{*}$; that is,

$$
A^{*}=k(p-c) \text {. }
$$

Lemma 2. Given price p, there exists a unique optimal order quantity factor $z^{*}$, and it satisfies

$$
F\left(z^{*}\right)=\frac{(1+\beta)(p-c+s)}{(1+\alpha)(c-v)+(1+\beta)(p-c+s)} .
$$

Furthermore, the optimal order quantity factor $z^{*}$ can be obtained; that is,

$$
z^{*}=F^{-1}\left[\frac{(1+\beta)(p-c+s)}{(1+\alpha)(c-v)+(1+\beta)(p-c+s)}\right] .
$$

Then we know that the optimal policy of the advertising effort level and order quantity is to order $Q^{*}$ units to sell at an exogenous price $p$ with the advertising effort level $A^{*}$, where $A^{*}$ is specified by Lemma 1 and $Q^{*}$ is specified by Lemmas 1 and 2 ; that is,

$$
\begin{aligned}
Q^{*}= & y(p)+k A^{*}+z^{*} \\
= & a-b p+k^{2}(p-c) \\
& +F^{-1}\left[\frac{(1+\beta)(p-c+s)}{(1+\alpha)(c-v)+(1+\beta)(p-c+s)}\right] .
\end{aligned}
$$

Since there is no direct evidence on the values of the loss aversion degree parameters, we conduct a sensitivity analysis to analyze the impact of the surplus loss aversion degree and the stockout loss aversion degree on the optimal order quantity and the advertising effort level. The general findings are presented as the following propositions.

Proposition 3. Given price p, the optimal advertising effort level $A^{*}$ is independent of the surplus and stockout loss aversion behaviors.

Proof. Since $A^{*}=k(p-c)$, if the price $p$ is exogenous, that is, the price $p$ is not related to the newsvendor's surplus and stockout loss aversion behaviors, then we have that the optimal advertising effort level $A^{*}$ is also unrelated to the newsvendor's surplus and stockout loss aversion behaviors.

Proposition 4. If $\alpha=\beta$, then the optimal order quantity $Q^{*}$ is irrelevant to both parameters $\alpha$ and $\beta$. In this situation, the optimal order quantity equals the loss-neutral order quantity.

Proof. If $\alpha=\beta$, by (25), we have

$$
\begin{aligned}
Q^{*} & =y(p)+k A^{*}+z^{*} \\
& =a-b p+k^{2}(p-c)+F^{-1}\left[\frac{p-c+s}{p-v+s}\right] ;
\end{aligned}
$$

thus, the order quantity is irrelevant to the stockout and surplus loss aversion behaviors and the optimal order quantity is the loss-neutral solution. 
Actually, because the stockout loss aversion and the surplus loss aversion require actions on the order quantity in the opposite directions, therefore, when the newsvendor exhibits equal aversions to the stockout loss and the surplus loss, the two loss aversions still affect the decisions but they offset each other. In the end, it shows the optimal option which is the same with the loss-neutral decision.

Proposition 5. If parameter $\alpha$ is not equal to parameter $\beta$, then the optimal order quantity $Q^{*}$ decreases with parameter $\alpha$.

Proof. According to (25), we know

$$
\begin{aligned}
\frac{\partial Q^{*}}{\partial \alpha} & =\frac{\partial z^{*}}{\partial \alpha} \\
& =-\frac{(1+\beta)(p-c+s)(c-v)}{[(1+\alpha)(c-v)+(1+\beta)(p-c+s)]^{2} f\left(z^{*}\right)} .
\end{aligned}
$$

Obviously, $\partial Q^{*} / \partial \alpha<0$, and the conclusion holds.

Proposition 6. If parameter $\alpha$ is not equal to parameter $\beta$, then the optimal order quantity $Q^{*}$ increases with parameter $\beta$.

Proof. According to (25), we know

$$
\begin{aligned}
\frac{\partial Q^{*}}{\partial \beta} & =\frac{\partial z^{*}}{\partial \beta} \\
& =\frac{(1+\alpha)(c-v)(p-c+s)}{[(1+\alpha)(c-v)+(1+\beta)(p-c+s)]^{2} f\left(z^{*}\right)} .
\end{aligned}
$$

Obviously, $\partial Q^{*} / \partial \beta>0$, and the conclusion holds.

It can be seen from (25) and above propositions that the optimal order quantity for the loss-averse newsvendor deviates systematically from the one for the loss-neutral newsvendor as shown in (26). Specifically, if the newsvendor is sensitive to the stockout loss but not sensitive to the surplus loss, that is, the effect of the surplus loss aversion on the decision can be neglected, then the loss-averse newsvendor will order more than the loss-neutral one, and the order quantity increases with the stockout loss aversion degree. Similarly, if the newsvendor is sensitive to the surplus loss but not sensitive to the stockout loss, that is, the effect of the stockout loss aversion on the decision can be neglected, then the lossaverse newsvendor will order less than the loss-neutral one, and the order quantity decreases with the surplus loss aversion degree. If the newsvendor is sensitive to both the stockout loss and surplus loss, the order quantity fluctuates around the loss-neutral one for the different degrees of the stockout loss aversion and the surplus loss aversion.

In order to show the scale of the effects of the two loss aversions on the optimal policy (since the advertising effort level is not related to the loss aversions, here we only analyze the scale of the effects of the loss aversions on the order quantity), an illustrative example is shown in Figure 4. In the example, the parameters are considered to be as follows:

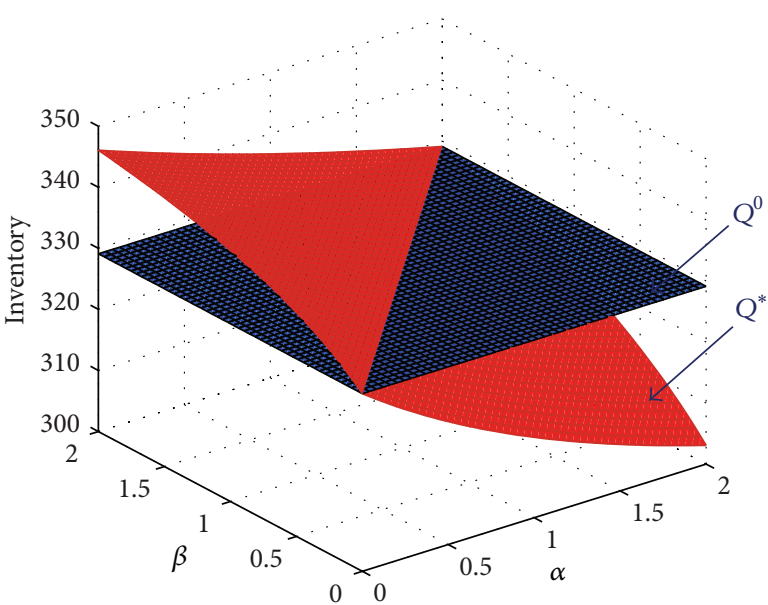

FIgURE 4: The effects of the loss aversions on the optimal order quantity.

$a=200, b=1.5, c=18, v=5, s=20, M=100, N=200$, and the exogenous price $p=30$, and the order quantity factor $\varepsilon$ follows the uniform distribution in $[M, N]$; that is, $\varepsilon \sim U[100,200]$. Since the degree of the loss aversion of the newsvendor is usually not greater than $2[17,18]$, we consider that the loss aversion parameters are in a reasonable range of $0 \leq \alpha \leq 2$ and $0 \leq \beta \leq 2$, and the tendency of the effect is fully reflected in this range.

We can see from Figure 4 that the order quantity of the loss-averse newsvendor $Q^{*}$ deviates from the one of lossneutral newsvendor $Q^{0}$ in systematic way as described in Propositions 3-6. When loss aversion is higher (less) than the one of the stockout loss aversion, that is, the newsvendor is more sensitive to the surplus loss aversion (stockout loss aversion), the order quantity $Q^{*}$ is lower (higher) than the loss-neutral one $Q^{0}$. When surplus loss aversion parameter is equal to the stockout loss aversion parameter, the order quantity $Q^{*}$ is equal to the loss-neutral one $Q^{0}$, and it is shown by the intersection line. Obviously, the effect of the surplus loss aversion on the order quantity is opposite to the one of stockout loss aversion. We can also see that, compared with the nonclassified loss aversion, the classified loss aversions, that is, surplus loss aversion and stockout loss aversion, show the clearer and more specific effects on the order quantity.

\section{Solutions under the Endogenous Price}

In some situations, the newsvendor may have the pricing power, and it is usually called endogenous price case. The endogenous price case is common in the monopoly market. In this section, we investigate the optimal solutions of the order quantity, price, and advertising effort level in different situations.

According to (13), the first- and second-order partial derivatives of $E[U]$ with respect to the price $p$ are obtained as follows:

$$
\begin{aligned}
& \frac{\partial E[U]}{\partial p}=a-2 b p+k A+\mu+b c-(1+\beta) \theta(z), \\
& \frac{\partial^{2} E[U]}{\partial p^{2}}=-2 b<0 .
\end{aligned}
$$


On the basis of the above analysis, we have Lemma 7 which follows directly from (29) and (30).

Lemma 7. For fixed advertising effort level $A$ and order quantity factor $z$, the optimal price is determined uniquely as a function of $A$ and $z$ :

$$
p^{*}=\frac{1}{2 b}[k A+a+\mu+b c-(1+\beta) \theta(z)] .
$$

In (31), since $p>c, \beta>\max [(k A+a+\mu-b c) / \theta(z)-1,0]$.

It can be seen from Lemmas 2 and 7 that the price is related directly to the stockout loss aversion parameter and is related indirectly to the surplus loss aversion parameter through order quantity factor $z$. It is necessary to point out that the effect of the price on the order quantity is the same as the one of the surplus loss aversion on the order quantity. Specifically, if the price is higher (lower), then the order quantity is less (greater); analogously, if the surplus loss aversion parameter is higher (lower), then the order quantity is less (greater) too.

In the following, we consider solving the model for the joint order quantity, price, and advertising effort level decisions in two cases: one is for $2 b \neq k^{2}$ and the other is for $2 b=k^{2}$. The specific solving processes are given below.

If $2 b \neq k^{2}$, then we substitute $A^{*}=A(p)$ and $p^{*}=p(z)$ into (13), and then the optimization problem $\max _{A, z, p} E[U(A$, $z, p)]$ is converted into an optimization problem with a single variable $z$, that is, $\max _{z} E\{U[A(p(z)), z, p(z)]\}$. Furthermore, we have Theorem 8 . For the convenience of the description, let $X(\cdot)=f(\cdot) /[1-F(\cdot)]$, and it is a hazard rate function.

Theorem 8. When $2 b \neq k^{2}$, if $F(\varepsilon)$ satisfies condition (a), $2 b-$ $k^{2}>0$ and $2 X(z)^{2}+d X(z) / d z>0$, or $(b), 2 b-k^{2}<0$ and $2 X(z)^{2}+d X(z) / d z<0$, then $z^{*}$ is the largest $z$ in the region $[M, N]$ that satisfies $\partial E[U(z, p(z))] / \partial z=0$. If $F(\varepsilon)$ satisfies condition (c), $2 b-k^{2}>0,2 X(z)^{2}+d X(z) / d z>0$, and $a+$ $\mu-b c+\left(2 b-k^{2}\right) s-(1+\beta)(\mu-M)>0$, or condition $(d)$, $2 b-k^{2}<0,2 X(z)^{2}+d X(z) / d z<0$, and $a+\mu-b c+(2 b-$ $\left.k^{2}\right) s-(1+\beta)(\mu-M)>0$, then $z^{*}$ is the unique $z$ in the region $[M, N]$ that satisfies $\partial E[U(z, p(z))] / \partial z=0$.

Proof. See Appendix.

Therefore, if $2 b \neq k^{2}$, then the optimal policy is to order $Q^{*}\left(Q^{*}=y\left(p^{*}\right)+k A+z^{*}\right)$ units to sell at the price $p^{*}$ with advertising effort level $A^{*}$, where $z^{*}$ is determined according to Theorem $8, A^{*}$ is specified by Lemma 1 , and $p^{*}$ is specified by Lemma 7 .

Analogously, if $2 b=k^{2}$, we have Theorem 9 .

Theorem 9. If $2 b=k^{2}$, then the policy is to order $Q^{*}$ units to sell at the price $p^{*}$ with the advertising effort level $A^{*}$, where $A^{*}$ is specified by Lemma $1, z^{*}$ is specified by Lemma 2, and $p^{*}$ is bound price.

Proof. See Appendix.

Therefore, if $2 b=k^{2}$, then the optimal policy is to order $Q^{*}\left(Q^{*}=y\left(p^{*}\right)+k A+z^{*}\right)$ units to sell at the price $p^{*}$ with advertising effort level $A^{*}$, where $p^{*}$ is determined according to Theorem $9, A^{*}$ is specified by Lemma 1 , and $z^{*}$ is specified by Lemma 2.

According to Theorems 8 and 9, the optimal solution of $p^{*}, A^{*}$, and $z^{*}$ can be determined. Then since $Q=y(p)+$ $k A+z$ and $y(p)=a-b p$, the optimal order quantity $Q^{*}$ with endogenous price is

$$
\begin{aligned}
Q^{*}= & y\left(p^{*}\right)+k A^{*}+z^{*} \\
= & a-b p^{*}+k^{2}\left(p^{*}-c\right) \\
& +F^{-1}\left[\frac{(1+\beta)\left(p^{*}-c+s\right)}{(1+\alpha)(c-v)+(1+\beta)\left(p^{*}-c+s\right)}\right] .
\end{aligned}
$$

In reality, the newsvendor may decide three decision variables simultaneously or may make decisions successively for some internal or external factors. For example, the newsvendor may have a fixed advertising investment for financial reasons, or the newsvendor may have unchangeable preference price for the competition reason, or the newsvendor may have a fixed order quantity factor such as the mean of $\varepsilon$. If simultaneously, the newsvendor's optimal policy can be obtained by Theorem 8 or Theorem 9. If successively, the newsvendor's optimal policy can be obtained by the following analysis.

Here, we provide the analysis of the optimal solutions when one of the three decision variables is fixed for some reasons and conduct it in the following three conditions.

(1) If the price $p$ is fixed, then the optimization problem $\max _{A, z, p} E[U(A, z, p)]$ can be converted into $\max _{A, z} E[U(A$, $z, p)]$, and the optimal solution of the advertising effort level $A$ and order quantity factor $z$ follows the one when the price is exogenous, discussed in Section 4.

(2) If the order quantity factor $z$ is fixed, then the optimization problem $\max _{A, z, p} E[U(A, z, p)]$ can be converted into $\max _{A, p} E[U(A, p)]$, and the optimal solution of the advertising effort level $A$ and retail price $p$ can be determined by the following discussion.

According to (13), the second-order mixed partial derivative of expected utility function is obtained below:

$$
\begin{aligned}
& \frac{\partial^{2} E[U]}{\partial p \partial A}=k \\
& \frac{\partial^{2} E[U]}{\partial A \partial p}=k
\end{aligned}
$$

Then, according to (19), (30), and (33), we have the Hessian matrix with respect to the price $p$ and the advertising effort level $A$; that is,

$$
H_{A p}=\left[\begin{array}{ll}
\frac{\partial^{2} E[U]}{\partial A^{2}} & \frac{\partial^{2} E[U]}{\partial A \partial p} \\
\frac{\partial^{2} E[U]}{\partial p \partial A} & \frac{\partial^{2} E[U]}{\partial p^{2}}
\end{array}\right]=\left[\begin{array}{cc}
-1 & k \\
k & -2 b
\end{array}\right] .
$$

For (34), we know that $\left|\partial^{2} E[U] / \partial A^{2}\right|=-1<0$ and $\left|H_{A p}\right|=2 b-k^{2}$. In the following, we conduct the analysis 
under the scenarios $2 b>k^{2}, 2 b=k^{2}$, and $2 b<k^{2}$, respectively.

(i) If $2 b>k^{2}$, then the Hessian matrix is negative definite. Therefore, if $2 b>k^{2}$, the constructed model is concave with respect to $A$ and $p$, and there exists uniquely joint optimal solution of $A$ and $p$ to maximize the newsvendor's utility. By (16) and (29), the optimal solution of $A$ and $p$ is determined; that is,

$$
\begin{aligned}
A^{*} & =\frac{k}{2 b-k^{2}}[a+\mu-b c-(1+\beta) \theta(z)], \\
p^{*} & =\frac{a+\mu+b c-k^{2} c}{2 b-k^{2}}-\frac{(1+\beta)}{2 b-k^{2}} \theta(z) .
\end{aligned}
$$

In (35) and (36), since $A^{*} \geq 0$ and $p^{*}>c$, we have $0 \leq \beta<$ $(a+\mu-b c) / \theta(z)-1$.

Therefore, when $2 b>k^{2}$, if $\beta$ satisfies $0 \leq \beta<(a+\mu-$ bc) $/ \theta(z)-1$, then the optimal solution of $A$ and $p$ exists as shown in (35) and (36); if not, there is no feasible solution.

Remark 10. If the order quantity factor $z$ is fixed and $2 b>k^{2}$, then there exists uniquely joint optimal solution of $A$ and $p$.

Proposition 11. Given $z^{*}$, the advertising effort level $A^{*}$ decreases with parameter $\beta$, but it is not related to parameter $\alpha$.

Proof. According to (35), we know

$$
\frac{\partial A^{*}}{\partial \beta}=-\frac{k \theta(z)}{2 b-k^{2}} .
$$

Apparently, $\partial A^{*} / \partial \beta \leq 0$, and the advertising effort level is not related to parameter $\alpha$.

Proposition 12. Given $z^{*}$, the endogenous price $p^{*}$ decreases with parameter $\beta$, but it is not related to parameter $\alpha$.

Proof. According to (36), we know

$$
\frac{\partial p^{*}}{\partial \beta}=-\frac{\theta(z)}{2 b-k^{2}} .
$$

Apparently, $\partial p^{*} / \partial \beta \leq 0$, and the price is not related to parameter $\alpha$.

Proposition 13. Given $z^{*}$, If $b \geq k^{2}$, then the order quantity $Q^{*}$ increases with parameter $\beta$, and if $k^{2} / 2<b<k^{2}$, then the order quantity $Q^{*}$ decreases with parameter $\beta$. The order quantity $Q^{*}$ is not related to parameter $\alpha$.

Proof. According to (35), (36), and $Q^{*}=y(p)+k A^{*}+z^{*}=$ $a-b p+k^{2}(p-c)+z$, we know

$$
\frac{\partial Q^{*}}{\partial \beta}=\frac{\left(b-k^{2}\right) \theta(z)}{2 b-k^{2}} .
$$

Since $2 b>k^{2}$, if $b \geq k^{2}, \partial Q^{*} / \partial \beta \geq 0$, if $k^{2} / 2<b<$ $k^{2}, \partial Q^{*} / \partial \beta<0$, and the order quantity is not related to parameter $\alpha$. (ii) If $2 b=k^{2}$, by (16) and (29), we have

$$
\begin{aligned}
a-2 b p+k A+\mu+b c-(1+\beta) \theta(z) & =0, \\
A^{*} & =k(p-c) .
\end{aligned}
$$

Then the optimal price can be arbitrary one in reasonable scale. Furthermore, the optimal advertising effort level can be determined; that is, $A^{*}=k\left(p^{*}-c\right)$. In this situation, the loss aversions cannot affect the optimal policy of price and advertising effort level.

(iii) If $2 b<k^{2}$, by (16) and (29), the optimal solutions of $A$ and $p$ can be determined, respectively; that is,

$$
\begin{aligned}
A^{*} & =\frac{k}{2 b-k^{2}}[a+\mu-b c-(1+\beta) \theta(z)], \\
p^{*} & =\frac{a+\mu+b c-k^{2} c}{2 b-k^{2}}-\frac{(1+\beta)}{2 b-k^{2}} \theta(z) .
\end{aligned}
$$

In (41), we have $\beta>\max [(a+\mu-b c) / \theta(z)-1,0]$ because of $A^{*} \geq 0, p^{*}>c$, and $\beta \geq 0$.

Therefore, when $2 b<k^{2}$, if $\beta$ satisfies $\beta>\max [(a+\mu-$ $b c) / \theta(z)-1,0]$, then the optimal solution of $A$ and $p$ exists, as shown in (41); if not, there is no feasible solution. In this situation, the advertising effort level $A^{*}$ and the endogenous price $p^{*}$ are related to the stockout loss aversion, but not to the surplus loss aversion.

(3) If the advertising effort level $A$ is fixed, then the optimization problem $\max _{A, z, p} E[U(A, z, p)]$ is converted into $\max _{z, p} E[U(z, p)]$, and then the optimal solution of the order quantity factor $z$ and price $p$ can be determined by the following discussion.

According to Lemmas 2 and 7 , we have $F\left(z^{*}\right)=(1+\beta)(p-$ $c+s) /((1+\alpha)(c-v)+(1+\beta)(p-c+s))$ and $p^{*}=p(z)=$ $(1 / 2 b)[k A+a+\mu+b c-(1+\beta) \theta(z)]$. By substituting $p^{*}=$ $p(z)$ into $F\left(z^{*}\right)$, optimization problem $\max _{z, p} E[U(z, p)]$ can be converted into the optimization problem with a single variable $z$, that is, $\max _{z} E\{U[A(p(z)), z, p(z)]\}$. Furthermore, we have Theorem 14.

Theorem 14. If $F(\varepsilon)$ satisfies the condition $2 X(z)^{2}+$ $d X(z) / d z>0$, then $z^{*}$ is the largest $z$ in the region $[M, N]$ that satisfies $\partial E[U(z, p(z))] / \partial z=0$. If $F(\varepsilon)$ satisfies the condition $2 X(z)^{2}+d X(z) / d z>0$ and $a+\mu-b c+k A+$ $2 b s-(1+\beta)(\mu-M)>0$, then $z^{*}$ is the unique $z$ in the region $[M, N]$ that satisfies $\partial E[U(z, p(z))] / \partial z=0$.

Proof. See Appendix.

Therefore, we know that if the advertising effort level $A$ is fixed, the optimal policy is to order $Q^{*}\left(Q^{*}=y\left(p^{*}\right)+\right.$ $\left.k A+z^{*}\right)$ units to sell at price $p^{*}$, where $z^{*}$ is determined according to Theorem 14 and $p^{*}$ is specified by Lemma 7. In this situation, the order quantity $Q^{*}$ and price $p^{*}$ are related to the stockout loss aversion and surplus loss aversion. In the following, we provide the sensitivity analysis of the effect of the loss aversions on the order quantity and the price when the unique solution exists. 
Proposition 15. Given $z^{*}$, the price $p^{*}$ decreases with parameter $\beta$, but it is not related to parameter $\alpha$.

Proof. Since the order quantity factor $z^{*}$ is fixed, according to Lemma 7 , we have that the price $p^{*}$ is not related to the parameter $\alpha$ and have

$$
\frac{\partial p^{*}}{\partial \beta}=\frac{-\theta(z)}{2 b} .
$$

Apparently, $\partial p^{*} / \partial \beta \leq 0$.

Proposition 16. Given $p^{*}$, the order quantity factor $z^{*}$ increases with parameter $\beta$ but decreases with parameter $\alpha$.

Proof. Since the price $p^{*}$ is fixed, according to Lemma 2, we have that

$$
\begin{aligned}
& \frac{\partial z^{*}}{\partial \beta}=\frac{(1+\alpha)(c-v)(p-c+s)}{[(1+\alpha)(c-v)+(1+\beta)(p-c+s)]^{2} f(z)}, \\
& \frac{\partial z^{*}}{\partial \alpha} \\
& \quad=-\frac{(1+\beta)(p-c+s)(c-v)}{[(1+\alpha)(c-v)+(1+\beta)(p-c+s)]^{2} f(z)} .
\end{aligned}
$$

Apparently, $\partial z^{*} / \partial \beta \geq 0$ and $\partial z^{*} / \partial \alpha \leq 0$.

\section{Managerial Insights}

According to the above analysis, we can give the managerial insights that may be helpful to the decision-makers in practical joint inventory, pricing, and advertising decisions. If the newsvendor exhibits the loss aversions, that is, the surplus and stockout loss aversions, then his/her decisions on the price, the order quantity, and the advertising effort level are different from the ones of the traditional newsvendor without considering the loss aversions.

In the case of the exogenous price (i.e., the price of the product depends on the market), the order quantity of the loss-averse newsvendor deviates from the one of the traditional newsvendor. Several interesting insights can be obtained as follows:

(a) If the newsvendor is concerned more about the surplus loss aversion, then his/her order quantity should be less than the one of the traditional newsvendor.

(b) If the newsvendor is concerned more about the stockout loss aversion, then his/her order quantity should be more than the one of the traditional newsvendor.

(c) Particularly, if the newsvendor's perceptions to the surplus loss aversion and the stockout loss aversion are the same, then his/her order quantity should be the same as the one of the traditional newsvendor.

In the case of the endogenous price (i.e., the price of the product depends on the newsvendor), the loss-averse newsvendor's decisions on the price, order quantity, and advertising effort level will be affected by the price elasticity and the advertising sensitive degree. Several interesting insights can be obtained below:

(a) If the relation between the price elasticity and the advertising sensitive degree meets the certain condition (see Theorem 9), then the price determined by the loss-averse newsvendor should be the bound price.

(b) If the demand is considered to be deterministic (i.e., the demand factor $\varepsilon$ takes a deterministic value), then the loss-averse newsvendor's decisions on the price and advertising effort level will depend on the price elasticity and advertising sensitive degree.

(c) If the newsvendor determines in advance his/her advertising effort level, then his/her decisions on the price and order quantity factor will depend on the surplus and stockout loss aversion degrees.

\section{Conclusions}

In this paper, we extend the classical newsvendor and pricing model to integrate advertising decisions and to take the stockout loss aversion and surplus loss aversion into account. We apply a linear utility function to depict the stockout loss aversion and surplus loss aversion and construct total utility function of the newsvendor by integrating the loss aversion utility function and the profit function. The newsvendor's expected utility is maximized by optimizing the order quantity, price, and advertising effort level policies. Then, we solve the model under the exogenous price case and the endogenous price case and obtain the optimal policy of the order quantity and the advertising effort level for exogenous price case and the optimal policy of the order quantity, price, and advertising effort level in some situations for endogenous price case. Furthermore, we provide the sensitivity analysis regarding the loss aversion parameters.

We find that the loss-averse solutions are different from the loss-neutral solutions since the loss aversion behaviors of a newsvendor affect the order quantity, pricing, and advertising decisions; specifically, the order quantity increases with the stockout aversion parameter and decreases with the surplus aversion parameter. For the exogenous price, the advertising effort level is not affected by the loss aversions of the newsvendor. When the degree of stockout loss aversion is equal to the degree of surplus loss aversion, the optimal order quantity is also not affected by the loss aversions. For the endogenous price, under the mild conditions, the policy of the order quantity, price, and the advertising effort level is related to the two loss aversions, and furthermore the policy is analyzed and given when the advertising effort level or order quantity factor is fixed. We also find that, compared with the nonclassified loss aversion, the classified loss aversions, that is, surplus loss aversion and stockout loss aversion, show the clearer and more specific effects on the order quantity, price, and the advertising effort level.

Compared with the existing research on loss-averse newsvendor problem, our work classifies the loss aversion 
into the surplus loss aversion and the stockout loss aversion and emphasizes the analysis of the impacts of two loss aversions on the optimal policy, respectively. In addition, the advertising effect is taken into account. Compared with the research on the advertising effect, our work focuses on the newsvendor problem and takes the loss aversions into account. Our study compensates them by clearly describing and modeling the surplus and stockout loss aversion effects or by considering the advertising effect.

For the further research, we will explore and analyze the behavioral factors which can affect the newsvendor's decisions and study how to determine the values of the behavioral parameters. It would also be interesting to conduct experimental studies to investigate the parameter scales of loss aversions.

\section{Appendix}

\section{Proof of Theorem 8.}

Proof of (i). According to (22) and (31), we have

$$
p=\frac{a+\mu+b c-k^{2} c}{2 b-k^{2}}-\frac{(1+\beta) \theta(z)}{2 b-k^{2}} .
$$

Then according to (15) and (A.1), we have

$$
\begin{aligned}
& \frac{d E[U(z, p(z))]}{d z}=-(1+\alpha)(c-v) F(z)+(1+\beta) \\
& \cdot\left[\frac{a+\mu+b c-k^{2} c}{2 b-k^{2}}-c+s-\frac{(1+\beta) \theta(z)}{2 b-k^{2}}\right] \\
& \cdot[1-F(z)] .
\end{aligned}
$$

Let $r(z)=d E\{U[z, p(z)]\} / d z$; then

$$
\begin{aligned}
& \frac{d r(z)}{d z}=\frac{(1+\beta)^{2}}{2 b-k^{2}}[1-F(z)]^{2}-\{(1+\alpha)(c-v) \\
& +(1+\beta) \\
& \left.\quad \cdot\left[\frac{a+\mu+b c-k^{2} c}{2 b-k^{2}}-c+s-\frac{(1+\beta) \theta(z)}{2 b-k^{2}}\right]\right\} \\
& \quad f(z) .
\end{aligned}
$$

Furthermore, $d^{2} r(z) / d z^{2}$ can be obtained as follows:

$$
\begin{aligned}
& \frac{d^{2} r(z)}{d z^{2}}=-\frac{3(1+\beta)^{2}[1-F(z)] f(z)}{2 b-k^{2}}-\{(1+\alpha) \\
& \cdot(c-v)+(1+\beta) \\
& \left.\cdot\left[\frac{a+\mu+b c-k^{2} c}{2 b-k^{2}}-c+s-\frac{(1+\beta) \theta(z)}{2 b-k^{2}}\right]\right\} \frac{d f(z)}{d z} \\
& =\frac{d r(z) / d z}{f(z)} \frac{d f(z)}{d z}
\end{aligned}
$$

$$
\begin{aligned}
& -\frac{(1+\beta)^{2}[1-F(z)] f(z)}{2 b-k^{2}}\left\{\frac{[1-F(z)][d f(z) / d z]}{f(z)^{2}}\right. \\
& +3\} .
\end{aligned}
$$

Since $d f(z) / d z=\left[d X(z) / d z-X(z)^{2}\right][1-F(z)]$, where $X(\cdot)=$ $f(\cdot) /[1-F(\cdot)]$, then (A.4) can be converted into

$$
\begin{aligned}
& \frac{d^{2} r(z)}{d z^{2}}=\frac{d r(z) / d z}{f(z)} \frac{d f(z)}{d z} \\
& \quad-\frac{(1+\beta)^{2}[1-F(z)] f(z)}{\left(2 b-k^{2}\right) X(z)^{2}}\left[2 X(z)^{2}+\frac{d X(z)}{d z}\right] .
\end{aligned}
$$

Then we have

$$
\begin{aligned}
& \left.\frac{d^{2} r(z)}{d z^{2}}\right|_{d r(z) / d z=0} \\
& =-\frac{(1+\beta)^{2}[1-F(z)] f(z)}{\left(2 b-k^{2}\right) X(z)^{2}}\left[2 X(z)^{2}+\frac{d X(z)}{d z}\right] .
\end{aligned}
$$

According to (A.6), if (a) $2 b-k^{2}>0$ and $2 X(z)^{2}+d X(z) / d z>$ 0 or (b) $2 b-k^{2}<0$ and $2 X(z)^{2}+d X(z) / d z<0$, then $d^{2} r(z) / d z^{2} \leq 0$, and it implies that $r(z)$ has at most two roots. Since $r(N)=-(1+\alpha)(c-v)<0$, if $r(z)$ has two roots, the smaller root corresponds to a local minimum of $E\{U[z, p(z)]\}$, and the larger one corresponds to a local maximum of $E\{U[z, p(z)]\}$; if $r(z)$ has only one root, it indicates that $r(z)$ is from positive to negative, and the root corresponds to a local maximum of $E\{U[z, p(z)]\}$; hence, $E\{U[z, p(z)]\}$ has only one local maximum. For two roots situation, the optimal value of $z$ is the larger one of two values of $z$ that satisfies $r(z)=d E\{U[z, p(z)]\} / d z=0$. For only one root situation, the optimal value of $z$ is the unique value that satisfies $r(z)=d E\{U[z, p(z)]\} / d z=0$. This completes the proof of (i).

Proof of (ii). Since $r(N)=-(1+\alpha)(c-v)<0$ and $E\{U[z, p(z)]\}$ is unimodal if $d f(z) / d z \geq X(z)$, if $r(M)>0$ holds, that is, $a+\mu-b c+\left(2 b-k^{2}\right) s-(1+\beta)(\mu-M)>0, E\{U[z, p(z)]\}$ has only one root. That is, if $a+\mu-b c+\left(2 b-k^{2}\right) s-(1+\beta)(\mu-$ $M)>0$, then there exists the uniquely optimal solution. This completes the proof of (ii).

Proof of Theorem 9. Since $2 b=k^{2}$, according to (22) and (29), we have

$$
\begin{aligned}
\frac{\partial E[U(p)]}{\partial p}= & a+\left(k^{2}-2 b\right) p+\mu+b c-k^{2} c \\
& -(1+\beta) \theta(z) \\
= & a+\mu+b c-k^{2} c-(1+\beta) \theta(z) .
\end{aligned}
$$

Then according to the (A.7), the second-order partial derivative of $E[U]$ with respect to the price $p$ is obtained as follows: 


$$
\begin{aligned}
& \frac{\partial E^{2}[U(p)]}{\partial p^{2}} \\
& \quad=\frac{(1+\beta)^{2}(1+\alpha)^{2}(c-v)^{2}}{[(1+\alpha)(c-v)+(1+\beta)(p-c+s)]^{3} f\left\{F^{-1}[(1+\beta)(p-c+s) /((1+\alpha)(c-v)+(1+\beta)(p-c+s))]\right\}}>0 .
\end{aligned}
$$

Since $\partial E^{2}[U(p)] / \partial p^{2}>0$, the expected utility function $E[U(p)]$ is convex, so the maximum of the expected utility can be obtained at bound prices.

\section{Proof of Theorem 14.}

Proof of (i). According to (15) and (31), we have

$$
\begin{aligned}
& \frac{d E[U(z, p(z))]}{d z}=-(1+\alpha)(c-v) F(z)+(1+\beta) \\
& \cdot\left[\frac{a+\mu+b c+k A}{2 b}-c+s-\frac{(1+\beta) \theta(z)}{2 b}\right] \\
& \cdot[1-F(z)] .
\end{aligned}
$$

Let $R(z)=d E\{U[z, p(z)]\} / d z$; then we have the secondorder derivative of $R(z)$; that is,

$$
\begin{aligned}
& \frac{d R(z)}{d z}=\frac{(1+\beta)^{2}}{2 b}[1-F(z)]^{2}-\{(1+\alpha)(c-v) \\
& +(1+\beta) \\
& \left.\quad \cdot\left[\frac{a+\mu+b c+k A}{2 b}-c+s-\frac{(1+\beta) \theta(z)}{2 b}\right]\right\} \\
& \quad \cdot f(z) .
\end{aligned}
$$

Furthermore, the second-order derivative of $R(z)$ can be obtained; that is,

$$
\begin{aligned}
& \frac{d^{2} R(z)}{d z^{2}}=-\frac{3(1+\beta)^{2}[1-F(z)] f(z)}{2 b}-\{(1+\alpha) \\
& \cdot(c-v)+(1+\beta) \\
& \left.\cdot\left[\frac{a+\mu+b c+k A}{2 b}-c+s-\frac{(1+\beta) \theta(z)}{2 b}\right]\right\} \frac{d f(z)}{d z} \\
& =\frac{d R(z) / d z}{f(z)} \frac{d f(z)}{d z} \\
& -\frac{(1+\beta)^{2}[1-F(z)] f(z)}{2 b}\left\{\frac{[1-F(z)][d f(z) / d z]}{f(z)^{2}}\right. \\
& +3\} .
\end{aligned}
$$

Since $d f(z) / d z=\left[d X(z) / d z-X(z)^{2}\right][1-F(z)]$, where $X(\cdot)=$ $f(\cdot) /[1-F(\cdot)]$, then $($ A.11) can be converted into

$$
\begin{aligned}
& \frac{d^{2} R(z)}{d z^{2}}=\frac{d R(z) / d z}{f(z)} \frac{d f(z)}{d z} \\
& -\frac{(1+\beta)^{2}[1-F(z)] f(z)}{2 b X(z)^{2}}\left[2 X(z)^{2}+\frac{d X(z)}{d z}\right] .
\end{aligned}
$$

Then we have

$$
\begin{aligned}
& \left.\frac{d^{2} R(z)}{d z^{2}}\right|_{d R(z) / d z=0} \\
& =-\frac{(1+\beta)^{2}[1-F(z)] f(z)}{2 b X(z)^{2}}\left[2 X(z)^{2}\right. \\
& \left.+\frac{d X(z)}{d z}\right] .
\end{aligned}
$$

According to (A.13), if $2 X(z)^{2}+d X(z) / d z>0$, then $d^{2} R(z) / d z^{2} \leq 0$, and it implies that $R(z)$ has at most two roots. Since $R(N)=-(1+\alpha)(c-v)<0$, if $R(z)$ has two roots, the smaller root corresponds to a local minimum of $E\{U[z, p(z)]\}$, and the larger one corresponds to a local maximum of $E\{U[z, p(z)]\}$; if $R(z)$ has only one root, it indicates that $R(z)$ is from positive to negative, and the root corresponds to a local maximum of $E\{U[z, p(z)]\}$; hence, $E\{U[z, p(z)]\}$ has only one local maximum. For two roots situation, the optimal value of $z$ is the larger one of two values of $z$ that satisfies $R(z)=d E\{U[z, p(z)]\} / d z=0$. For only one root situation, the optimal value of $z$ is the unique value that satisfies $R(z)=d E\{U[z, p(z)]\} / d z=0$. This completes the proof of (i).

Proof of (ii). Since $R(N)=-(1+\alpha)(c-v)<0$ and $E\{U[z, p(z)]\}$ is unimodal if $d f(z) / d z \geq Y(z)$, on the basis of this, if $R(M)>0$ holds, that is, $a+\mu-b c+k A+2 b s-$ $(1+\beta)(\mu-M)>0, E\{U[z, p(z)]\}$ has only one root. That is, if $a+\mu-b c+k A+2 b s-(1+\beta)(\mu-M)>0$, then there exists the unique optimal solution. This completes the proof of (ii).

\section{Competing Interests}

The authors declare that there is no conflict of interests regarding the publication of this paper. 


\section{Acknowledgments}

The research was partly supported by the National Natural Science Foundation of China (Project nos. 71271049, 71271051, and 71571039) and the Fundamental Research Funds for the Central Universities, NEU, China (Project no. N140607001).

\section{References}

[1] Y. F. Chen, X. M. Su, and X. B. Zhao, "Modeling bounded rationality in capacity allocation games with the quantal response equilibrium," Management Science, vol. 58, no. 10, pp. 1952-1962, 2012.

[2] Y. F. Chen and X. B. Zhao, "Decision bias in capacity allocation games with uncertain demand," Production and Operations Management, vol. 24, no. 4, pp. 634-646, 2015.

[3] X. Wu and J. A. Niederhoff, "Fairness in selling to the newsvendor," Production and Operations Management, vol. 23, no. 11, pp. 2002-2022, 2014.

[4] F. Gino and G. Pisano, "Toward a theory of behavioral operations," Manufacturing and Service Operations Management, vol. 10, no. 4, pp. 676-691, 2008.

[5] C.-Y. Lee, X. Li, and M. Yu, "The loss-averse newsvendor problem with supply options," Naval Research Logistics, vol. 62, no. 1, pp. 46-59, 2015.

[6] X. M. Su, "Bounded rationality in newsvendor models," Manufacturing \& Service Operations Management, vol. 10, no. 4, pp. 566-589, 2008.

[7] M. Becker-Peth, E. Katok, and U. W. Thonemann, "Designing buyback contracts for irrational but predictable newsvendors," Management Science, vol. 59, no. 8, pp. 1800-1816, 2013.

[8] P. K. Kopalle, P. K. Kannan, L. B. Boldt, and N. Arora, "The impact of household level heterogeneity in reference price effects on optimal retailer pricing policies," Journal of Retailing, vol. 88, no. 1, pp. 102-114, 2012.

[9] M. E. Schweitzer and G. P. Cachon, "Decision bias in the newsvendor problem with a known demand distribution: experimental evidence," Management Science, vol. 46, no. 3, pp. 404420, 2000.

[10] T. H. Cui, J. S. Raju, and Z. J. Zhang, "Fairness and channel coordination," Management Science, vol. 53, no. 8, pp. 1303-1314, 2007.

[11] Y. Liu, C. Ding, C. Fan, and X. Chen, "Pricing decision under dual-channel structure considering fairness and free-riding behavior," Discrete Dynamics in Nature and Society, vol. 2014, Article ID 536576, 10 pages, 2014.

[12] Y. F. Ren and R. Croson, "Overconfidence in newsvendor orders: an experimental study," Management Science, vol. 59, no. 11, pp. 2502-2517, 2013.

[13] L. Chen, A. G. Kök, and J. D. Tong, "The effect of payment schemes on inventory decisions: the role of mental accounting," Management Science, vol. 59, no. 2, pp. 436-451, 2013.

[14] F. Herweg, "The expectation-based loss-averse newsvendor," Economics Letters, vol. 120, no. 3, pp. 429-432, 2013.

[15] J. Sun and X. Xu, "Coping with loss aversion in the newsvendor model," Discrete Dynamics in Nature and Society, vol. 2015, Article ID 851586, 11 pages, 2015.

[16] U. Schmidt and H. Zank, "What is loss aversion?" The Journal of Risk and Uncertainty, vol. 30, no. 2, pp. 157-167, 2005.
[17] C. X. Wang and S. Webster, "The loss-averse newsvendor problem,” Omega, vol. 37, no. 1, pp. 93-105, 2009.

[18] C. X. Wang, “The loss-averse newsvendor game," International Journal of Production Economics, vol. 124, no. 2, pp. 448-452, 2010.

[19] D. E. Bell, "Disappointment in decision making under uncertainty," Operations Research, vol. 33, no. 1, pp. 1-27, 1985.

[20] G. Loomes and R. Sugden, "Disappointment and dynamic consistency in choice under uncertainty," The Review of Economic Studies, vol. 53, no. 2, pp. 271-282, 1986.

[21] B. Koszegi and M. Rabin, "Reference-dependent risk attitudes," American Economic Review, vol. 97, no. 4, pp. 1047-1073, 2007.

[22] D. Y. Wu and K.-Y. Chen, "Supply chain contract design: impact of bounded rationality and individual heterogeneity," Production and Operations Management, vol. 23, no. 2, pp. 253-268, 2014.

[23] M. Nagarajan and S. Shechter, "Prospect theory and the newsvendor problem," Management Science, vol. 60, no. 4, pp. 10571062, 2014.

[24] W. Liu, S. Song, B. Li, and C. Wu, "A periodic review inventory model with loss-averse retailer, random supply capacity and demand," International Journal of Production Research, vol. 53, no. 12, pp. 3623-3634, 2015.

[25] L. J. Ma, Y. X. Zhao, W. L. Xue, T. C. E. Cheng, and H. M. Yan, "Loss-averse newsvendor model with two ordering opportunities and market information updating," International Journal of Production Economics, vol. 140, no. 2, pp. 912-921, 2012.

[26] X. Xu, Z. Meng, R. Shen, M. Jiang, and P. Ji, "Optimal decisions for the loss-averse newsvendor problem under CVaR," International Journal of Production Economics, vol. 164, pp. 146159, 2015.

[27] S. Du, T. Nie, C. Chu, and Y. Yu, "Newsvendor model for a dyadic supply chain with nash bargaining fairness concerns," International Journal of Production Research, vol. 52, no. 17, pp. 5070-5085, 2014.

[28] X. Long and J. Nasiry, "Prospect theory explains newsvendor behavior: the role of reference points," Management Science, vol. 61, no. 12, pp. 3009-3012, 2015.

[29] N. C. Petruzzi and M. Dada, "Pricing and the newsvendor problem: a review with extensions," Operations Research, vol. 47, no. 2, pp. 183-194, 1999.

[30] M. J. Khouja, "Optimal ordering, discounting, and pricing in the single-period problem," International Journal of Production Economics, vol. 65, no. 2, pp. 201-216, 2000.

[31] S. A. Raza and M. Turiac, "Joint optimal determination of process mean, production quantity, pricing, and market segmentation with demand leakage," European Journal of Operational Research, vol. 249, no. 1, pp. 312-326, 2016.

[32] A. A. Taleizadeh and M. Noori-Daryan, "Pricing, manufacturing and inventory policies for raw material in a three-level supply chain," International Journal of Systems Science, vol. 47, no. 4, pp. 919-931, 2016.

[33] Y. Qin, R. Wang, A. J. Vakharia, Y. Chen, and M. M. Seref, "The newsvendor problem: review and directions for future research," European Journal of Operational Research, vol. 213, no. 2, pp. 361-374, 2011.

[34] A. N. Sadigh, S. K. Chaharsooghi, and M. Sheikhmohammady, "A game theoretic approach to coordination of pricing, advertising, and inventory decisions in a competitive supply chain," Journal of Industrial and Management Optimization, vol. 12, no. 1, pp. 337-355, 2016. 
[35] F. El Ouardighi, G. Feichtinger, D. Grass, R. Hartl, and P. M. Kort, "Autonomous and advertising-dependent 'word of mouth' under costly dynamic pricing," European Journal of Operational Research, vol. 251, no. 3, pp. 860-872, 2016.

[36] P. D. Berger and T. Magliozzi, "Optimal co-operative advertising decisions in direct-mail operations," Journal of the Operational Research Society, vol. 43, no. 11, pp. 1079-1086, 1992.

[37] S. Karray and G. Zaccour, "Effectiveness of coop advertising programs in competitive distribution channels," International Game Theory Review, vol. 9, no. 2, pp. 151-167, 2007.

[38] Z. Wu, W. Zhu, and P. Crama, "The newsvendor problem with advertising revenue," Manufacturing and Service Operations Management, vol. 13, no. 3, pp. 281-296, 2011.

[39] S. Karray and S. H. Amin, "Cooperative advertising in a supply chain with retail competition," International Journal of Production Research, vol. 53, no. 1, pp. 88-105, 2015.

[40] G. Aust and U. Buscher, "Cooperative advertising models in supply chain management: a review," European Journal of Operational Research, vol. 234, no. 1, pp. 1-14, 2014.

[41] J. Zhang, Q. Gou, L. Liang, and Z. Huang, "Supply chain coordination through cooperative advertising with reference price effect," Omega, vol. 41, no. 2, pp. 345-353, 2013.

[42] J. Yang, J. Xie, X. Deng, and H. Xiong, "Cooperative advertising in a distribution channel with fairness concerns," European Journal of Operational Research, vol. 227, no. 2, pp. 401-407, 2013.

[43] P. Zipkin, Foundations of Inventory Management, McGraw-Hill Higher Education, New York, NY, USA, 2000.

[44] W. Chung, S. Talluri, and R. Narasimhan, "Price markdown scheme in a multi-echelon supply chain in a high-tech industry," European Journal of Operational Research, vol. 215, no. 3, pp. 581-589, 2011.

[45] F. Bernstein, F. Chen, and A. Federgruen, "Coordinating supply chains with simple pricing schemes: the role of vendormanaged inventories," Management Science, vol. 52, no. 10, pp. 1483-1492, 2006.

[46] W. Chung, S. Talluri, and R. Narasimhan, "Optimal pricing and inventory strategies with multiple price markdowns over time," European Journal of Operational Research, vol. 243, no. 1, pp. 130-141, 2015.

[47] Y. Yu, G. Q. Huang, and L. Liang, "Stackelberg game-theoretic model for optimizing advertising, pricing and inventory policies in vendor managed inventory (VMI) production supply chains," Computers \& Industrial Engineering, vol. 57, no. 1, pp. 368-382, 2009.

[48] M. Khouja and S. S. Robbins, "Linking advertising and quantity decisions in the single-period inventory model," International Journal of Production Economics, vol. 86, no. 2, pp. 93-105, 2003.

[49] B. Liu, X. Ma, and R. Zhang, "Joint decision on pricing and advertising for competing retailers under emergency purchasing," Economic Modelling, vol. 39, no. 1, pp. 257-264, 2014.

[50] W. Chu and P. S. Desai, "Channel coordination mechanisms for customer satisfaction," Marketing Science, vol. 14, no. 4, pp. 343359, 1995.

[51] P. S. Desai, "Advertising fee in business-format franchising," Management Science, vol. 43, no. 10, pp. 1401-1419, 1997.

[52] S. P. Sigué and P. Chintagunta, "Advertising strategies in a franchise system," European Journal of Operational Research, vol. 198, no. 2, pp. 655-665, 2009.

[53] D. Kahneman and A. Tversky, "Prospect theory: an analysis of decision under risk," Econometrica, vol. 47, no. 2, pp. 263-291, 1979.
[54] G. Loomes and R. Sugden, "Regret theory: an alternative theory of rational choice under uncertainty," The Economic Journal, vol. 92, no. 368, pp. 805-824, 1982.

[55] R. Engelbrecht-Wiggans and E. Katok, "Regret in auctions: theory and evidence," Economic Theory, vol. 33, no. 1, pp. 81-101, 2007.

[56] X. Chen, G. Hao, and L. Li, "Channel coordination with a lossaverse retailer and option contracts," International Journal of Production Economics, vol. 150, pp. 52-57, 2014.

[57] Z. P. Fan, X. Zhang, F. D. Chen, and Y. Liu, "Multiple attribute decision making considering aspiration-levels: a method based on prospect theory," Computers \& Industrial Engineering, vol. 65, no. 2, pp. 341-350, 2013.

[58] M. Braun and A. Muermann, "The impact of regret on the demand for insurance," Journal of Risk and Insurance, vol. 71, no. 4, pp. 737-767, 2004. 


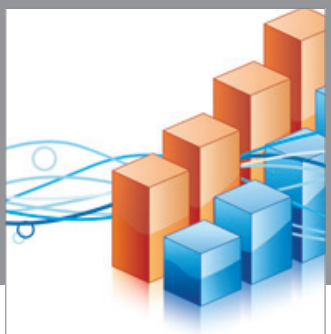

Advances in

Operations Research

vatem alat4

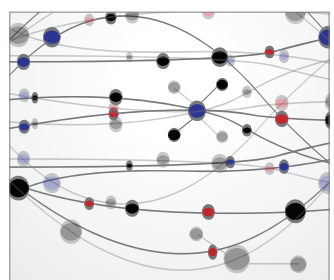

\section{The Scientific} World Journal
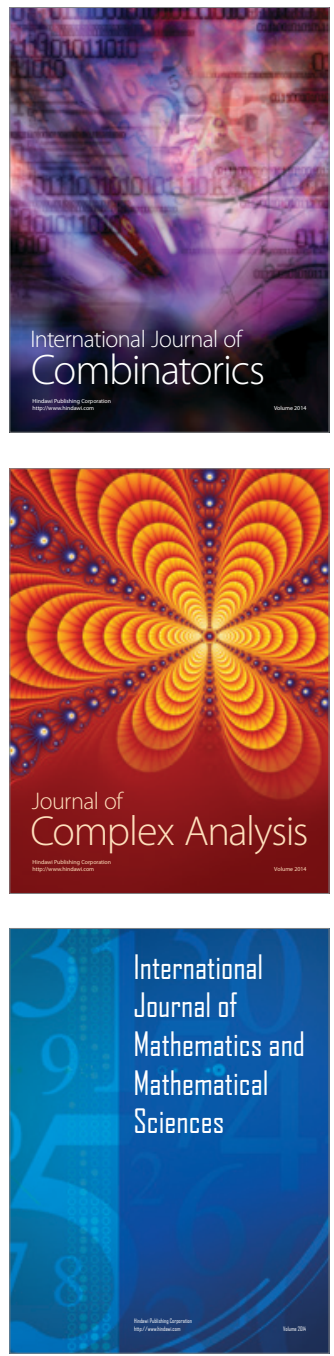
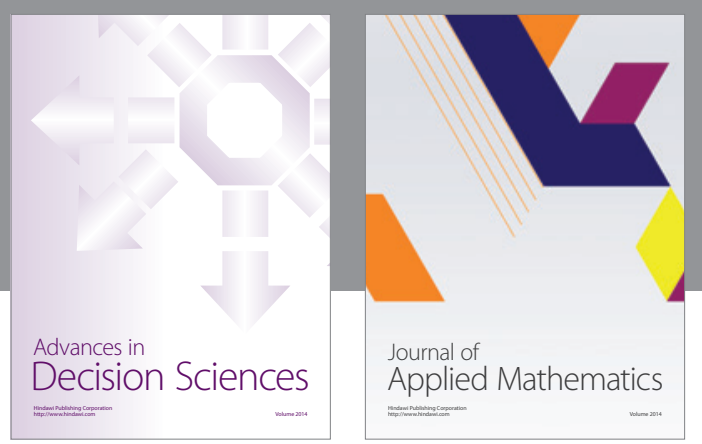

Algebra

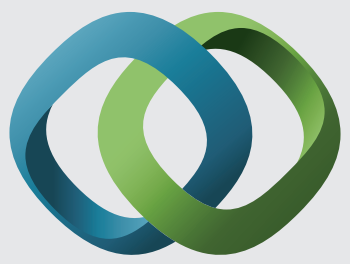

\section{Hindawi}

Submit your manuscripts at

http://www.hindawi.com
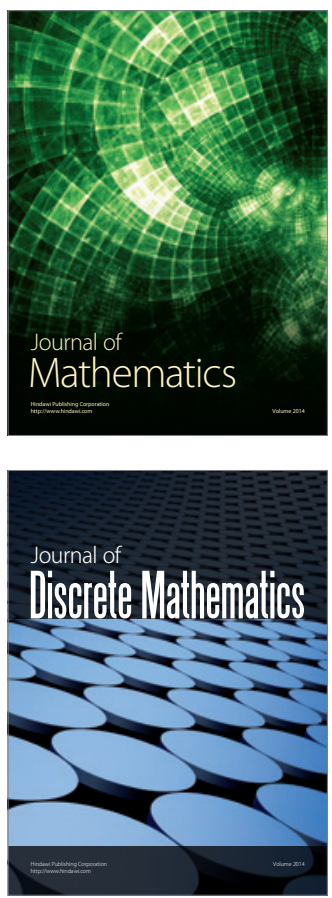

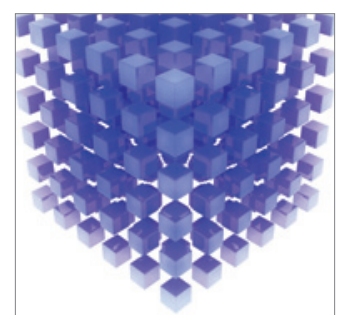

Mathematical Problems in Engineering
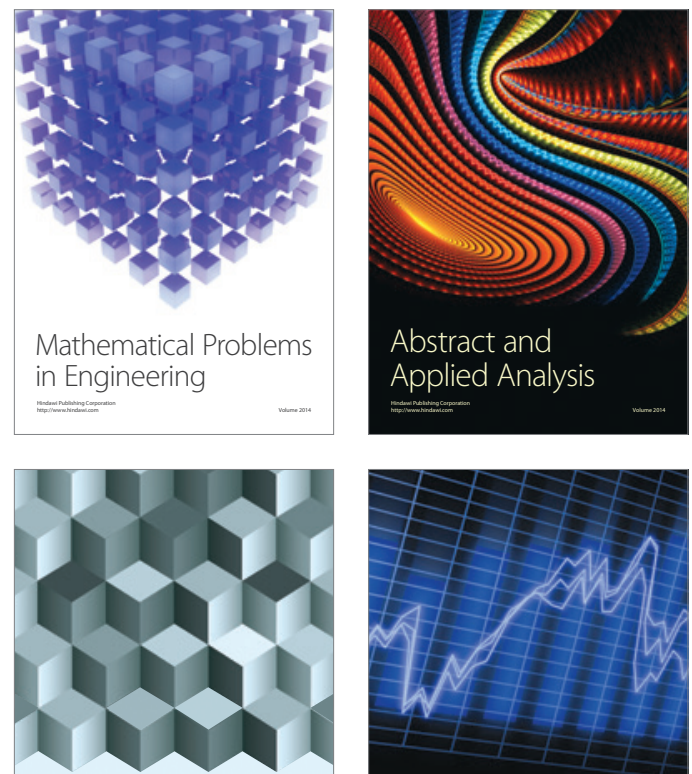

Journal of

Function Spaces

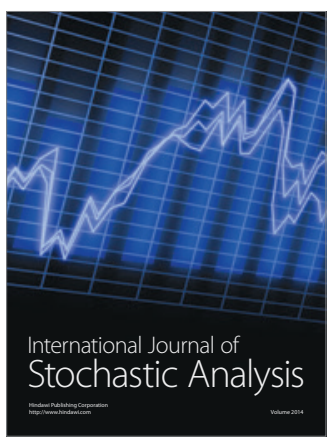

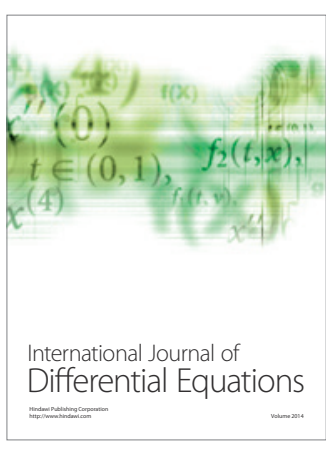
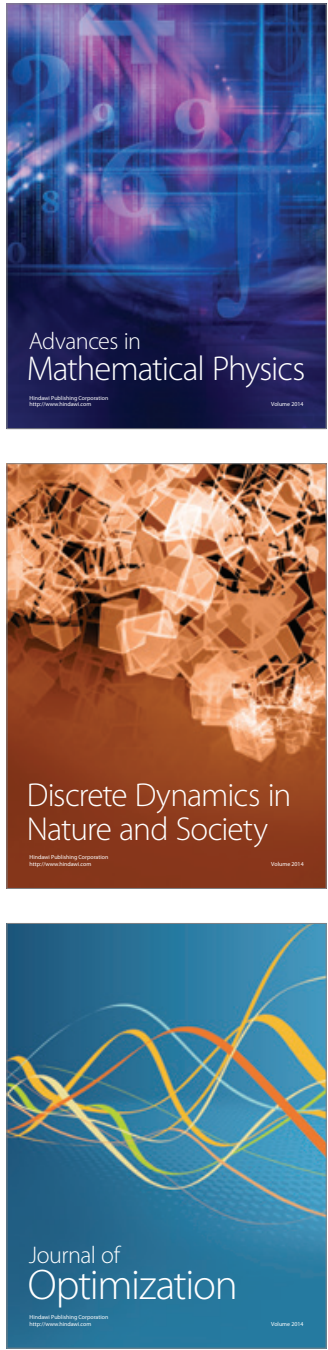